\title{
Infant Sleep Development: Location, Feeding and Expectations in the Postnatal Period
}

\author{
Charlotte K. Russell ${ }^{*}$, Lyn Robinson and Helen L. Ball
}

Parent-Infant Sleep Lab, Durham University, University Boulevard, Thornaby, Stockton-on-Tees, TS17 6BH, UK

\begin{abstract}
Coping with sleep disruption is a common difficulty faced by new parents. Here we take a critical, contextual and evolutionary perspective on recent evidence surrounding the development of normal infant sleep in the postnatal period, its relationship with feeding method and the relevance of sleep location. Firstly, we explore the question of defining 'normal' infant sleep, considering the timing of sleep consolidation, cross-cultural and historical perspectives, and the impact of feeding method on infant waking and parental tiredness. In the second part of the review we focus on infant sleep location, physiological and behavioural functioning and sleep safety. We summarise recent research exploring the consequences of alternate infant sleep locations, including in-hospital interventions testing the effect of these sleep locations on outcomes associated with mother-infant proximity. Finally we provide an up-to-date review of SIDS research, including case-control and cross-cultural studies that inform policy-creation and authoritative advice to parents. We find that many researchers still neglect crucial variables affecting infant sleep including sleep location and feeding method and conclude that whilst the field of infant sleep research is well-established, future studies would benefit from consideration of infant evolutionary biology and the heterogeneity of infant care practices, which would lead to valuable new research insights in understanding normal infant sleep.
\end{abstract}

Keywords: Infant sleep development, infant sleep location, infant feeding method, parental expectations, parental tiredness.

\section{INTRODUCTION}

One of the most difficult issues new parents face is how to cope with lack of sleep. Parents are rarely well-prepared for the degree of sleep disruption a newborn infant engenders, and many have unrealistic expectations about the first few postnatal months. The ensuing sleep deprivation and eventual 'desperation' to get a 'good night's sleep' leave parents vulnerable to implementing advice and devising strategies that may in the short term put their infants in danger, and in the long term have undesirable consequences for lifetime health. Much myth and poor evidence surround the issue of infant sleep. This review aims to provide an overview of the most recent clinical evidence on the normal sleep of young infants and their parents, and to situate this evidence within a broad evolutionary and cross-cultural framework. This approach highlights how notions regarding 'normal infant sleep' become distorted when viewed solely via western biomedical perspective, and emphasises the need for a recalibration of parental and clinical expectations surrounding the sleep of young infants.

\section{SLEEPING THROUGH THE NIGHT}

'The saying 'I slept like a baby' is reflective of the lack of understanding about patterns of infant sleep exhibited in the neonatal period' $\mathrm{p} 711$ [1].

*Address correspondence to this author at the Parent-Infant Sleep Lab, Durham University, University Boulevard, Thornaby, Stockton-on-Tees, TS17 6BH, UK; Tel: 0191334 0794; Fax: 019133 40249;

E-mail: c.k.russell@durham.ac.uk
For newborn infants, who spend up to 16-18 hours per day asleep, sleep does not occur predominantly at night, nor does it last all night; rather it is distributed more or less evenly between day and night occurring in 2-3 hour bouts [2], becoming gradually concentrated in night-time hours as the infant's circadian rhythm develops [3]. Furthermore, newborn sleep states are not limited to simply 'being asleep' versus 'being awake'. Infants experience 'quiet sleep' (characterised by regular respiration in the absence of rapid eye movement (non-REM) and gross muscle movements) and 'active sleep' (characterised by variable respiration alongside the presence of REM) [4]. Within the first three months postpartum, over $50 \%$ of infant sleep time is spent in an active sleep state $[5,6]$ compared to $15-20 \%$ of adult sleep [7]. Infants experience a greater proportion of active sleep than adults as a consequence of the rapid brain development that occurs during the first year of life [8-10].

Historically, guidelines regarding the development of what constitutes 'normal' infant sleep have been largely based upon the research of Moore and Ucko [11] who reported that in a sample of approximately 160 infants, $70 \%$ began sleeping through the night at the age of 3 months. This finding subsequently became codified in paediatric texts and advice guides for parents as 'infants should start sleeping through the night from 3 months of age' [12]. There are 3 important points to note about Moore and Ucko's original research however. Firstly, 'sleeping through the night' was defined as a 5-hour stretch of sleep from midnight to $5 \mathrm{am}$, where the infant did not cry or 'fuss' to such an extent to wake the parents. A feature of the infant care fashions of the time, however, was that parents placed their infants in a 
separate room to sleep, which led to infant wake time being underestimated [13]. Secondly, 3 months was the time point at which $70 \%$ of infants began to experience consolidated night-time sleep bouts, meaning that $30 \%$ did not begin to do so until later. Furthermore, Moore and Ucko do not state that 3-month old infants were regularly experiencing consolidated sleep bouts, in fact, irrespective of the age when the infants' parents believed they began to sleep through the night, Moore and Ucko reported that half reverted back to night waking. Thirdly, Moore and Ucko's studies occurred at a time when infants were predominantly fed dairy-based formula - the implications of which are discussed further below. The popular notion that infants at 3 months old can and should be sleeping through the night is therefore erroneous.

More recently research conducted by Henderson et al. [14] sought to reinvestigate infant nocturnal sleep development from birth to 12 months. Infant sleep was assessed by 3 criteria involving the commencement of unbroken sleep: 1) from $12 \mathrm{am}$ to $5 \mathrm{am}$, as specified by Moore and Ucko [11]; 2) for a single 8 hour stretch; and 3) between $10 \mathrm{pm}$ to $6 \mathrm{am}$, in congruence with adult sleep schedules. In replication of Moore and Ucko, Henderson et al. defined the onset of successful settling to be when self-regulated sleep (which was defined to include a combination of sustained sleep and periods of quiet wakefulness) occurred in the absence of parent intervention. They found that at 3 months $58 \%$ of infants met criterion 1 , at 4 months $58 \%$ met criterion 2, and at 5 months $53 \%$ met criterion 3; they concluded that criterion 3 should be used by clinicians to define "sleeping through the night" for infants from 4 months old as it is "met by $50 \%$ of infants at 5 months of age, is congruent with family sleep patterns, and falls within typical sleep times" (p1086). Inferences made by Henderson et al. regarding what constitutes consolidated infant sleep are limited, however [15], because the authors did not differentiate between, or control for, infant sleep location (parental or separate room) or type of feeding method (human milk vs. formula). Both factors impact real and perceived infant sleep duration.

Research has begun to highlight differences in infant sleep patterns and development between breastfed and formula fed infants. Breastfed infants experience a more fragmented sleep [16], shorter sleeping bouts [17, 18] and begin to experience consolidated sleep later than formula fed infants [19]. Quillan [20] reported that although breastfed infants experience more nocturnal awakenings, no difference was found in total sleep duration compared with formula fed infants. The characteristics of human milk composition [21] and production [22] require infants to feed frequently, throughout the day and the night [23]. In contrast, the sleep patterns of formula-fed infants are a consequence of human infants' difficulty in digesting cow's milk, causing deeper and longer periods of sleep, earlier in life, compared to those who are breastfed [24]. Formula fed infants are less easily aroused from active sleep than breastfed infants [24]. Arousal from sleep is believed to be an important survival mechanism for infants against potentially fatal respiratory or cardiac perturbations that may affect victims of sudden infant death syndrome (SIDS) [24-27]. Breastfeeding has been reported to be protective against SIDS, the effect of which is stronger for exclusively breastfed infants [28, 29].
Our increasing understanding of the differences between breastfed and formula fed infant sleep suggests that encouraging early infant sleep consolidation undermines maternal lactation physiology, denies breastfed infants necessary nutrient intake, and may place arousal-deficient infants at an increased risk of SIDS.

\section{PARENTAL TIREDNESS}

Following birth, first-time mothers' sleep patterns change more dramatically than those of multiparous mothers [30]. Gress et al. [31] suggest that maternal perceptions of their own sleep quality are affected by the number of infantrelated sleep disruptions, rather than the duration of infant care during the night. Tiredness (a temporary state, relieved by a single sleep period) and fatigue (which continues despite rest, persisting through circadian rhythms) are commonly reported by parents in the postpartum period. Both are attributed to infant-related sleep disturbance, and have negatively been associated with maternal physical and mental well-being $[32,33]$. Furthermore, maternal tiredness is a commonly cited reason for the early termination of breastfeeding [34-36] and introduction of formula feeding. Changes in infant feeding are often driven by parental efforts to promote sleep duration for both their infant and themselves and to share night-time feeding responsibilities [37-39]. Minimising sleep disruption during the early postpartum period is not only a key concern for parents, but also for health-care providers in promoting the overall health and well-being of parents, and in supporting mothers in exclusively breastfeeding for at least 6 months as recommended by current health guidelines [40, 41]. But do parents of breastfed infants really experience less sleep and report more tiredness than those parents whose infants are not breastfed?

Recent research using actigraphy found that in exclusively breastfeeding families, both parents obtained greater overall sleep duration, in comparison to formula feeding families [39]. Other research has reported that there is no difference in total maternal sleep duration between different infant feeding practices [42, 43], despite reports that breastfeeding mothers experience more nocturnal wakening [37] and lower sleep efficiency [44]. Dørheim et al [30] found that mothers who exclusively breastfed experienced better quality sleep than mothers who combination fed (where infant receives both human and formula milk) and sleep quality did not differ from mothers who solely gave their infants formula milk. Furthermore, breastfeeding mothers who sleep in close proximity to their infants obtain more sleep and report more weeks of breastfeeding than women who combine breastfeeding with separate mother-infant sleep locations [37, 45]. Parents therefore implement a variety of strategies to balance their own needs with those of their infants.

\section{A CROSS-CULTURAL AND HISTORICAL VIEW OF INFANT SLEEP}

Around the world, infant sleep habits and environments are demonstrably different from those experienced by the majority of Western infants. Mindell et al. [46] reported that in Asian countries, infants ( $0-3$ years) had a significantly shorter total sleep time than infants from Euro-American countries. 
Furthermore, young Asian infants were significantly more likely to room-in (share the same room for sleep) and co-sleep with their parents, whereas for Euro-American infants, rooming-in was only prevalent in the early postnatal period and decreased with increasing infant age. Customs such as mother-infant sleep separation are characterised as child neglect by Mayan parents [47], and 'unkind' by Italian parents [48]. In many non-Western populations, infant sleep occurs in the presence of continual mother-infant contact, regardless of time of day or night; as infant sleep takes place on the mother's body or close to her, often in some form of carrying device during the day, and in her sleep space at night. Infants fall asleep while their mothers work and/or complete their daily activities. These infants do not require silence or darkness to sleep, and they are not expected or 'trained' to conform to a schedule [49-51]. Within Western societies prior to the late nineteenth century, mother-infant sleep contact was also the norm, as demonstrated by comments found in physicians' child-rearing guides for mothers [52].

The practice of mother-infant separation for sleep was associated with two historical developments associated with the rise of medical science: 1) the invention of anaesthesia for operations and its application in childbirth;2) the invention of artificial infant food based upon chemically altered cow's milk. During the $19^{\text {th }}$ century, the development and use of anaesthesia during childbirth, such as chloroform and 'twilight sleep' (combination of the narcotic morphine, and the amnesiac scopolamine), rendered women unconscious and disorientated during labour and delivery [53, 54]. Recovery from birth was a long process as the anaesthesia left women unable to perform basic infant care practices [55]. As a result, mother-infant separation became routine practice after birth, and infants were placed in hospital nurseries to be cared for by staff where their food intake (predominantly formula milk) could be 'scientifically managed' [56]. Infant care practices incorporating mother-infant separation and formula feeding soon extended to the home environment. In a magazine article published in 1934 titled, "Feeding the new baby," Regina J. Woody, describes the experience of bringing an infant home from the hospital. Woody writes, "Once you are at home and the baby safely tucked into his little crib, you will be confronted, almost immediately, with the practical necessity of warming and giving some of the formula which the hospital has so kindly provided" $\mathrm{p} 9$ [57].

These dramatic changes in postnatal and infant care practices became routine throughout the twentieth century and led to drastic decline in breastfeeding initiation rates [58]. It wasn't until the 1980s when researchers recognised the serious health ramifications of mother-infant postnatal separation $[59,60]$ and of feeding infants with formula milk [61-63] that seemingly 'beneficial improvements' in birth and infant care practices came under scrutiny. In recent years, much of this scrutiny has focussed on the impact upon early mother-infant interactions of disruption caused by hospital routines, and on the consequences of infant sleep environments in the hospital and at home.

\section{SLEEP, DISRUPTION, AND SEPARATION IN EARLY INFANCY}

The importance of mother-infant close contact in promoting sleep, establishing breastfeeding, and providing optimal conditions for maternal and infant well-being, is apparent in the minutes and hours immediately following delivery. In Western societies, this is a time when most new mothers (especially first-time mothers) are in delivery suites or postnatal wards, in the company of other new mothers and clinical staff (doctors, nurses, midwives) but in the absence of close family and community members [64, 65]. For many mother-infant dyads, the effects of labour analgesia remain for some time following birth; hospital noise, lighting and routine procedures are both unfamiliar and out of mothers' control; mothers and infants may be physically separated by hospital furniture, as well as by policy and procedures; and mothers are often unsure of themselves, being both inexperienced in child care, and lacking social contact with more experienced individual members of their family or community. This, therefore, is an environment far removed from that which humans have evolved to expect, both psychologically and physically. The negative consequences of hospital birth, including lack of sleep, reduced breastfeeding and maternal dissatisfaction with the birth/post-birth experience are, at least in part, consequences of mother-infant separation in the immediate and early postnatal period, and of disruption occurring in the postnatal ward environment that inhibits mothers and babies from behaving in an instinctive manner. Morrison et al. [66], for example, documented the effects of postnatal-ward disruption on the mother-infant dyad, recording a mean of 54 interruptions per participant during the 12-hour observation period ( $8 \mathrm{am}$ to $8 \mathrm{pm}$ on postnatal day 1), lasting an average of 17 minutes each. These "frequent, erratic, and lengthy" (p713) interruptions, and the concomitant lack of private, quiet time alone with their family, were described as extremely disruptive by mothers in this study and others [35, $67,68]$.

In addition to disruption by postnatal ward routines, an increasing body of research - particularly involving pre-term or low birth weight babies - suggests that mother-infant separation during infant sleep may have detrimental effects on both the immediate well-being and long-term development of infants [69-73]. A recent study compared healthy, full-term, two-day old neonates sleeping in skin-toskin contact with their mother, and then sleeping separately swaddled in a bassinet close to the mother's bed [74] Although reporting on a small sample $(\mathrm{n}=16)$, results showed that newborn infants sleeping separately from their mothers experienced less quiet sleep, and longer sleep latency (time to enter quiet sleep) than infants sleeping in skin-to-skin contact with their mother, with a $176 \%$ increase in heart-rate variability power (high- and low-frequency combined) during separate sleep. For both quiet (mean difference \pm SE $=.625 \pm .185, \mathrm{p}=.031$ ) and active (mean difference $\pm \mathrm{SE}=$ $1.787 \pm .485, \mathrm{p}=.001$ ) sleep, low-frequency power was significantly higher during separate sleep. High frequency power was significantly higher during separation in active sleep (mean difference $\pm \mathrm{SE}=1.028 \pm .254, \mathrm{p}=.001$ ) but not in quiet sleep (mean difference $\pm \mathrm{SE}=.684 \pm .442, \mathrm{p}=.219$ ); the lack of statistical significance of the latter probably due to inadequate power ( $\mathrm{n}=6$ babies entering quiet sleep during separation). The authors suggest that these findings are indicative of 'anxious arousal' in infants sleeping apart from their mothers. The results suggest that there are potentially harmful consequences of maternal-infant separation in the 
immediate postpartum period, building upon a large body of studies in primates and other non-human animals in which the harmful effects of maternal-infant separation have been observed [75-78].

The challenge for policy-makers and healthcare professionals therefore, is to establish ways in which the immediate postnatal environment can be made more conducive to promotion of sleep, bonding, initiation of breastfeeding, and the emotional and developmental wellbeing of the mother-infant dyad. Aside from recommendations such as: rooming-out if desired and longer hospital stays [79], the use of private rooms, bundling of routine tasks, avoidance of non-essential checks, aggressive treatment of pain, and provision of quiet family time [79] along with user-controlled interventions such as the use of privacy signs [80] have been proposed. In our own research, we have examined the impact of infant sleep location on sleep, feeding and well-being at the beginning of life, on the postnatal ward.

\section{MATERNAL AND INFANT SLEEP ON THE POSTNATAL WARD}

In many contemporary hospitals, following a period of skin-to-skin contact after birth, mother-infant contact is facilitated by 'rooming-in', where infants remain with the mother for the duration of her hospital stay and sleep in a bassinette at her bedside. The benefits of rooming-in in hospital were demonstrated in the late 1980s and early 1990s in a number of key studies [59, 60, 81-83] which showed that rooming-in facilitates mother-infant contact, enabling mothers to perform all aspects of their infant's care [84], and that mother-infant separation at night does not result in an increase in either the quantity or quality of maternal sleep or in maternal alertness the following day [59, 83]. They also showed that removing infants to nurseries resulted in significantly less infant sleep and more crying than for infants remaining in their mothers' rooms [60]; less frequent breastfeeding [81]; and greater likelihood of breastfeeding failure [82]. Twenty-four-hour rooming-in is now standard practice in progressive and WHO/UNICEF Baby-Friendly accredited hospitals worldwide.

Following the success of rooming-in interventions, the question of precisely where babies should sleep within that environment came to the fore in the mid-2000s. Both evolutionary theory and a tranche of research studies [85-89] pointed towards a shared sleep surface for mothers and babies being a normal human infant sleep location; one which both mothers and newborn infants had evolved to expect, and which is associated with a range of physiological outcomes for infants and mothers. Close contact improves breastfeeding outcomes, reduces infant crying, benefits mother-infant attachment and promotes cardio-respiratory stability [90]. Improved breastfeeding outcomes are explained by rapid maternal response to infant feeding cues resulting in more frequent suckling in the early newborn period and greater prolactin stimulation. This in turn influences the timing of lactogenesis II (milk 'coming in'), the amount of milk produced, and sustainable galactopoeisis (the long-term maintenance of lactation), all of which are controlled by the hormone prolactin [91-99]; a hormone triggered in greater quantity during night-time feeds compared to day-time feeds [100, 101].

Ball et al. [102] examined the effects of infant sleep location on the postnatal ward of a tertiary level hospital in the North-East of England. Sixty-one newly-delivered mother infant dyads were randomised to one of three conditions - infant in a standard cot, or standalone bassinet; infant in the mother's hospital bed, with bed-rail; infant in a 'side-car crib' - a 3-sided bassinet attaching to the mothers' hospital bed and videoed throughout the first two postnatal nights. Participants were followed up by telephone interview at $2,4,8$, and 16 weeks. Mother-infant dyads allocated to both side-car crib and mother's bed conditions made significantly more attempts to breastfeed than dyads allocated to the standalone bassinet condition, however across all 3 groups mothers and infants experienced no difference in total sleep duration. Separate standalone bassinets for infant sleep introduced a number of impediments to mother-infant night-time interaction: the presence of the cot wall hindered infants' rooting behaviour, prevented infants from initiating suckling, and obscured infant feeding cues from mothers. The study therefore showed that postnatal ward sleeping arrangements affected breastfeeding initiation. Although follow-up data from this study also suggested that long-term breastfeeding duration may also be affected, the subsequent North-East Cot Trial (NECOT) comparing breastfeeding duration for 870 mothers-infant pairs randomly allocated to standalone bassinet and side-car crib found no significant difference between the two conditions [103]. Where infants sleep in hospital, therefore, is an important variable in determining the success of breastfeeding initiation, but not breastfeeding duration - the latter appears to be more strongly related to sleeping arrangements in the home.

\section{INFANT SLEEP LOCATION AT HOME}

Once home, parents face challenges related to where to place their infants for sleep: many mothers cope with disruption to their sleep by sharing a bed with their baby for all or part of the night, whilst others choose to locate their infant alone in a separate room, believing lone sleeping to be less dangerous than bed-sharing [104].

Many authorities recommend that babies should sleep in a cot in the parents' room [105]. This recommendation is based largely on the results of SIDS-risk studies which have attributed a higher risk of SIDS to sleeping in a room alone, and/or sharing a bed with parents, compared to sleeping on a separate surface in the parents' room [106-112]. There may be additional benefits to room-sharing at home, in improving maternal responsiveness and ease of night-time care including breastfeeding, compared to separate sleeping [113]. A limitation of research to date, however, is that most studies which focus on the latter aspects of increased mother-infant proximity have only made comparisons of bed-sharing and sleeping in a separate room, rather than comparing room sharing with sleeping in separate rooms, so knowledge of such benefits remains hypothetical.

Parent-infant bed-sharing is a key strategy adopted by mothers seeking to cope with their infants' requirements for frequent waking and breastfeeding at night. A study examining the night-time behaviour of 233 families in the 
North-East of England during the first 4 postnatal months $[37,45]$, found that $65 \%$ of infants who had been 'ever breastfed' had bed-shared with their parent(s), while $33 \%$ of formula-fed infants had done so. For infants that were breastfed for more than one month, the proportion of bedsharing was even higher, at $72 \%$. Similar results have been seen in other studies in Western societies [18, 86, 114-118] indicating that bed-sharing is an important night-time care strategy for a substantial proportion of parents, and that it is especially significant in the context of breastfeeding. Results from the NECOT trial showed that participants who had reported bed-sharing at home in the first 13 weeks postnatally were half as likely as those who had reported no bed-sharing to have ceased breastfeeding at any given point [103], and other studies report a similar association [86-88, $117,119]$.

Parents choose to bed-share for a number of reasons [45, $87,120]$ in addition to ease of night-time feeds: allowing mother and baby to bond; more sleep for mother and baby; easier night-time parenting, especially if baby is unsettled or unwell; less infant crying; and reassurance for both mother and baby. Recent research from the US and Canada shows that mothers who choose to bed-share do so with an awareness of the potential risks associated with it [121, 122]. Sleeping in close-contact may also facilitate homeostatic regulation in the infant $[85,90,123]$. Video studies in home, hospital and laboratory settings have contributed remarkably consistent data on precisely how mothers and infants behave in a bed-sharing environment [88, 102, 124-127]. Postnatal ward video studies demonstrate that immediately following birth, when bed-sharing with their infants, breastfeeding mothers instinctively place their infants supine, on the bed (below the level of any pillows), level with their breasts. The mother's position in the bed is a protective one, curled around her infant in a ' $C$ ' shape. With her arm above the infant's head and her knees drawn up under its feet, she protects it from environmental hazards such as cold, heat, bedding and bed-partners. Mothers and infants predominantly face each other during the night; infants remain within touching distance of their mother at all times; and mothers and infants display increased sleep synchrony compared to sleeping apart [128].

\section{INFANT SLEEP HAZARDS}

Mother-infant shared sleep behaviour appears to be instinctive, and has intimate ties to the physiological processes underpinning lactation [37, 104, 128]. Some authorities oppose bed-sharing as an infant care strategy, however, [129-131] based on epidemiological studies that have reported bed-sharing to be a risk factor in SIDS and sudden unexpected death in infancy (SUDI). Some studies indicate that the majority of the risk can be explained by an interaction between bed-sharing and other risk factors, particularly smoking and alcohol consumption [107, 112]. Sleeping together on an unsafe surface - especially a sofa or couch - is also an important risk factor [112. Blabey and Gessner [132] examined 13 years of data on Alaskan infant deaths while bed-sharing to assess the contributions of known risk factors. In $99 \%$ of cases at least one additional risk was present including maternal tobacco use (75\%) and sleeping with an impaired person (43\%).
A number of other studies identify bed-sharing as a significant independent risk factor [109, 133-136]. Vennemann et al. $[134,135]$, for instance, concluded from a large German case-control study that bed-sharing with an adult was an independent risk factor for SIDS; however neither parental alcohol consumption nor the clothes worn by infants were included in the analyses, and both are important modifiable factors relevant to SIDS risk [112]. As infant feeding method is generally not included in calculations of bed-sharing risk; bed-sharing is combined with known high risk environments (sofas) for statistical purposes [112]; the prevalence of bed-sharing in the general population is underestimated [137]; and criteria used to define bed-sharing are inconsistent [108-110] it is impossible to evaluate whether there is any risk associated with breastfeedingrelated bed-sharing. Overall the evidence to date suggests no substantial increased risk of SIDS or SUDI for breastfed infants bed-sharing in the absence of sofa-sharing, parental smoking, alcohol consumption or drug use. Whilst no studies have shown bed-sharing to be associated with a reduced risk of SIDS [138], a recent meta-analysis has confirmed the role of breastfeeding in doing so [28].

Although it is not possible to ascribe a causal relationship between bed-sharing and breastfeeding it seems likely that a positive feedback loop exists, and the two behaviours are mutually reinforcing: bed-sharing facilitates frequent feeding which maintains or improves milk supply, while breastfeeding introduces oxytocin into the mother's blood and milk, reducing mothers' blood pressure [139] and inducing sleep for both mother and infant [101, 140]. Bedsharing thus enables breastfeeding mothers to cope more easily with frequent night time feeds, getting more sleep and continuing to breastfeed for longer.

It is important, however, for researchers and policymakers to recognise that 'bed-sharing' as a variable does not represent a homogenous category of behaviour and, as outlined above, that all bed-sharing is not equal in its safety. As Ball [45] demonstrates, bed-sharing does not occur as an 'all or nothing' strategy - many infants start the night in a cot beside their parents' bed, being brought into the bed for a feed and there remaining for part or all of the rest of the night. Parents may also find themselves bed-sharing unintentionally, in unplanned circumstances, having brought the baby into bed or, in a more risky scenario, onto a couch or sofa to feed, there falling asleep with their baby [112, 122]. Additionally each bed-sharing night is unique, even within families; the developmental and physiological characteristics of infants and parents change from night to night, along with exposure to risk factors such as other individuals present in the bed, smoking, alcohol or drugs. The characteristics of who bed-shares also changes over time, with those most likely to bed-share in early infancy being, as a group, at low risk of SIDS and high likelihood to breastfeed [141]. Recent research in the North of England [142] has also revealed the importance of cultural differences in infant care practices. Where parents choose for their infants to sleep, and how hazards are experienced within infant sleep environments, vary not only with feeding method, but also with cultural and socio-economic background, demonstrating the importance of tailoring the advice given to parents according to local and individual 
circumstances, and of sensitivity to culturally or ethnicallymediated infant sleep practices.

\section{IMPLICATIONS AND EXPECTATIONS}

Parental choice of feeding method, and of sleep location for their infant, is influenced by a suite of factors addressed in this review: cultural background or ideology; perceptions of the normality (or abnormality) of infants' sleep behaviour; infants' developmental stage; the tiredness of one or both parents. As clinical and lay interest in determining an empirical basis for infant care practices grows, and campaigners, policy makers and advisors work to make sense of an ever-increasing body of research, the way in which normal infant sleep is conceptualised and infant sleep environments are assessed is in need of re-evaluation. Researchers, policy-makers and those in a position to advise parents on sleeping arrangements for their babies must recognise the strength and intricacy of the relationship between infant sleep and feeding. Infant feeding method and sleep location influence and interact not just with each other, but with a whole host of factors relating to infant and parental well-being, from maternal mental health, to development of normal and healthy stress responses in infants, to long-term physiological gains for both mother and infant resulting from breastfeeding. Parents have a right to be informed about the strengths and limitations of the research upon which recommendations are made, and to know that whatever the prevailing cultural perspective on their infants' behaviour, fragmented sleep, frequent feeding and a need to be close to a caregiver are normal aspects of human infant sleep. Understanding that such behaviour is normal, rather than somehow pathological or deviant, goes a long way toward enabling parents to cope during the early postpartum period.

\section{CONFLICT OF INTEREST}

The authors confirm that this article content has no conflicts of interest.

\section{ACKNOWLEDGEMENTS}

Declared none.

\section{REFERENCES}

[1] Rosen L. Infant sleep and feeding. J Obstet Gynecol Neonatal Nurs 2008; 37(6): 706-14.

[2] Gertner S, Greenbaum C, Sadeh A, Dolfin Z, Sirota L, Ben-Nun Y. Sleep-wake patterns in preterm infants and 6 month's home environment: implications for early cognitive development. Early Hum Dev 2002; 68: 93-102.

[3] Parmelee A, Wenner W, Schultz H. Infant sleep patterns: from birth to 16 weeks of age. Pediatrics 1964; 65(4): 576-82.

[4] Prechtl HF. The behavioral states of the newborn infant (a review). Brain Res 1974(76): 185-212.

[5] Tarullo A, Balsam P, Fifer W. Sleep and infant learning. Infant Child Dev 2011; 20(1): 35-46.

[6] Anders TF, Sadeh A, Appareddy V. Normal sleep in neonates and children. In: Ferber M, Kyger M, Eds. Principles and practice of sleep medicine in the child. Philidephia: Saunders Company 1995; pp. 7-18.

[7] Peireno P, Algarín C, Uauy R. Sleep-wake states and their regulatory mechanisms throughout early human development. J Pediatrics 2003; 143(4): 70-9.

[8] Graven S, Browne J. Sleep and brain development: The critical role of sleep in fetal and early neonatal brain development. Newborn Infant Nurs Rev 2008; 8(4): 173-9.
[9] Frank MG. The ontogeny and function(s) of REM sleep. In: Mallick BN, Perumal SR, McCarley RW, Morrison AR, Eds. Rapid eye movement sleep. Cambridge: Cambridge University Press 2011.

[10] Marks G, Shaffery J, Oksenberg A, Speciale S, Roffwarg H. A functional role for REM sleep in brain maturation. Behav Brain Res 1995; 69(1-2): 1-11.

[11] Moore T, Ucko C. Night waking in early infancy. Arch Dis Child 1957; 32: 333-42.

[12] Gardens BHa. Baby Book. New York: Bantam 1965.

[13] Anders TF. Night waking in infants during the first year of life. Pediatrics 1979; 63(6): 860-4.

[14] Henderson JMT, France KG, Owens JL, Blampied NM. Sleeping through the night: The consolidation of self-regulated sleep across the first year of life. Pediatrics 2010; 126(5): e1081-e7.

[15] McKenna JJ, Ball HL. Early infant sleep consolidation is unnecessary barrier to breastfeeding (e-letter). Pediatrics 2010; 126(5): e1081-e7.

[16] Tikotzky L, De Marcas G, Har-Toov J, Dollberg S, Bar-Haim Y, Sadeh A. Sleep and physical growth in infants during the first 6 months. J Sleep Res 2010; 19: 103-10.

[17] Super CM, Harkness S, van Tijen N, van der Vlugt E, Dykstra J, Flintelman M. The three R's of Dutch child rearing and the socialization of infant arousal. In: Harkness S, Super CM, Eds. Parents' cultural belief systems: their origins, expressions, and consequences. New York: Guilford Press 1996.

[18] Elias M, Nicholson N, Bora C, Johnston J. Sleep/Wake patterns of breast-fed Infants in the first 2 years of life. Pediatrics 1986; 77(3): 322-9.

[19] Touchette E, Petit D, Paquet J, et al. Factors associated with fragmented sleep at night across early childhood. Arch Pediatr Adolesc Med 2005; 159(3): 242-9.

[20] Quillian S. Infant and mother sleep patterns during 4th postpartum week. Issues Compr Pediatr Nurs 1997; 20(2): 115-23.

[21] Neville MC. Volume and caloric density of human milk. In: Jensen RG, Ed. Handbook of milk composition. USA: Academic Press 1995; pp. 99-111.

[22] Kent JC, Mitoulas LR, Cregan MD, Ramsay DT, Doherty DA, Hartmann PE. Volume and frequency of breastfeedings and fat content of breast milk throughout the day. Pediatrics 2006; 117(3): e387-95.

[23] Anuntaseree W, Mo-suwan L, Vasiknanonte P, Kuasirikul S, Ma-alee A, Choprapawon C. Factors associated with bed sharing and sleep position in Thai neonates. Child Care Health Dev 2008; 34(4): 482-90.

[24] Horne RSC, Parslow PM, Ferens D, Watts A, Adamson TM. Comparison of evoked arousability in breast and formula fed infants. Arch Dis Child 2004; 89: 22-5.

[25] Hunt CE. The cardiorespiratory control hypothesis for sudden infant death syndrome. Clin Perinatol 1992; 19(4): 757-71.

[26] Mosko S, Richard C, McKenna J, Drummond S. Infant sleep architecture during bedsharing and possible implications for SIDS. Sleep 1996; 19(9): 677-84.

[27] Mosko S, Richards C, McKenna J. Infant arousals during mother infant bed sharing : implications for infant sleep and sudden infant death syndrome research. Pediatrics 1997; 100(5): 841-50.

[28] Hauck F, Thompson J, Tanabe K, Moon R, Venetian M. Breastfeeding and reduced risk of sudden infant death syndrome: A meta-analysis. Pediatrics 2011; 128: 103 -10.

[29] Vennemann MM, Bajanowski T, Brinkmann B, et al. Does Breastfeeding Reduce the Risk of Sudden infant Death Syndrome? Pediatrics 2009; 123(3): e406-e10.

[30] Dørheim SG, Bonevik GT, Eberhard-Gran M, Bjorvatn B. Sleep and depression in postpartum women: A population-based study. Sleep 2009; 32(7): 847-55.

[31] Gress JL, Chamber AS, Ong JC, Tikotzky L, Okada RL, Manber R. Maternal subjective sleep quality and nighttime infant care. J Reprod Infant Psychol 2010; 28(4): 384-91.

[32] Gaillo R, Rose N, Vittorino R. Fatique, wellbeing and parenting in mothers of infants and toddlers with sleep problems. J Reprod Infant Psychol 2011; 29(3): 236-49.

[33] Ansara D, Cohen M, Gallop KR, Schei B. Predictors or women's physical health problems after childbirth. J Psychosom Obstet Gynaecol 2005; 26(2): 115-25.

[34] Heinig MJ. Addressing maternal fatigue: A challenge to in-hospital breastfeeding promotion. J Hum Lact 2010; 26(3): 231-2. 
[35] Kurth E, Spichiger E, Zemp Stutter E, Biedermann J, Wheels I, Kennedy $\mathrm{H}$. Crying babies, tired mothers - challenges of the postnatal hospital stay: an interpretive phenomenological study. BMC Pregnancy Childbirth 2010; 10: 21.

[36] Tarrant RC, Younger KM, Sheridan-Pereira M. Factors associated with duration of breastfeeding in Ireland: Potential areas for improvement. J Hum Lact 2011; 27: 262-77.

[37] Ball HL. Breastfeeding, bed-sharing and infant sleep. Birth 2003; 30(3): 181-8.

[38] Pinilla T, Birch LL. Help me make it through the night: behavioral entrainment of breast-fed infants' sleep patterns. Pediatrics 1993; 91(2): 436-44.

[39] Doan T, Gardiner A, Gay CL, Lee KA. Breast-feeding increases sleep duration of new parents. J Perinat Neonatal Nurs 2007; 21(3): 200-6.

[40] Kramer MS, Kakuma R. Optimal duration of exclusive breastfeeding. Cochrane Database Syste Rev 2002; (1): CD003517.

[41] Department of Health. Off to the best start: Important information about feeding your baby. London: Department of Health 2007.

[42] Montgomery-Downs HE, Clawges HM, Santy EE. Infant feeding methods and maternal sleep and daytime functioning. Pediatrics 2010; 126(6): e1562-e8.

[43] Gay CL, Lee KA, Lee S. Sleep patterns and fatigue in new mothers and fathers. Biol Res Nurs 2004; 5(4): 311-8.

[44] Blyton DM, Sullivan CE, Edwards N. Lactation is associated with an increase in slow-wave sleep in women. J Sleep Res 2002; 11: 297-303.

[45] Ball HL. Reasons to bed-share: why parents sleep with their infants. J Reprod Infant Psychol 2002; 20(4): 207-22.

[46] Mindell JA, Sadeh A, Wiegane B, How TH, Goh DYT. Crosscultural difference in infant and toddler sleep. Sleep Med 2010; 11: 274-80.

[47] Morelli G, Oppenheim D, Rogoff B, Goldsmith D. Cultural variation in infants sleeping arrangements: questions of independance. Dev Psychol 1992; 28(4): 604-13.

[48] Wolf AW, Lozoff B, Latz S, Paludetto R. Parental theories in the management of young children's sleep in japan, italy and the united states. In: Harkness S, Super CM, Eds. Parents' Cultural Belief Systems. London: The Guildford Press 1996.

[49] Gantley M, Davies D, Murcott A. Sudden infant death syndrome: Links with infant care practices. Br Med J 1993; 306: 16-20.

[50] Whiting JWM. Environmental constraints on infant care practices. In: Munroe RH, Munroe RL, Whiting BB, Eds. Handbook Crosscultural Human Develop. New York: Garland 1981.

[51] Ball HL. Night-time infant care: cultural practice, evolution, and infant development. In: Liamputtong P, Ed. Childrearing and infant care issues: A cross-cultural perspective. Melbourne, Australia: Nova 2006; pp. 47-61.

[52] Hardyment C. Dream babies: Child care from locke to spock. London: Jonathan Cape Ltd 1983.

[53] Leavitt J. Birthing and anaesthesia: The debate over twilight sleep. J Women Cult Soc 1980; 2: 147-64.

[54] Caton D. What a blessing she had chloroform: The medical and social response to the pain of childbirth form 1800 to the present. New Haven: Yale University Press 1999.

[55] Nusche J. Lying in. Can Med Assoc J 2002; 167: 675-6.

[56] Ball HL, Ed. Evolutionary Paediatrics: a case study in applying Darwinian Medicine. New York: Taylor \& Francis 2008.

[57] Foss L. Perpetuating the scientific motherhood: The medicalization of infant feeding in parents magazine, 1930-2007. Chicago Int Comm Association Health Communication Div 2010.

[58] Wright A, Schanler R. The resurgence of breastfeeding at the need of the second millennium. J Nutr 2001; 131: 412-5.

[59] Keefe M. The impact of infant rooming-in on maternal sleep at night. J Obstet Gynecol Neonatal Nurs 1988; 17(2): 122-6.

[60] Keefe M. Comparisons of neonatal night time sleep-wake patterns in nursery versus rooming environments. Nurs Res 1987; 36(3): 140-4.

[61] Popkin B, Adair L, Black R, et al. Breast-feeding and diarrhoeal morbidity. Pediatrics 1990; 86: 874-82.

[62] Ford RP, Taylor BJ, Mitchell EA, et al. Breastfeeding and the risk of sudden infant death syndrome. Int J Epidemiol 1993; 22(5): 88590.

[63] Howie PW, Stewart Forsyth J, Ogston SA, Clark A, du V Florey C. Protective effect of breast feeding against infection. $\mathrm{Br}$ Med J 1990; 300: 11-6.
[64] Trevathan W, McKenna J. Evolutionary environments of human birth and infancy: insights to apply to contemporary life. Child Environ 1994; 11(2): 88-104.

[65] Jordan B, Davis-Floyd R. Birth in four cultures : a crosscultural investigation of childbirth in Yucatan, Holland, Sweden, and the United States. Prospect Heights, Ill: Waveland Press 1993.

[66] Morrison B, Ludington-Hoe S, Cranston Anderson G. Interruptions to breastfeeding dyads on postpartum day 1 in a University Hospital. J Obstet Gynecol Neonatal Nurs 2006; 35(6): 709-16.

[67] McLachlan H, Forster D, Yelland J, Rayner JL. Is the organisation and structure of hospital postnatal care a barrier to quality care? Findings from a state-wide review in Victoria, Australia. Midwifery 2008; 24(3): 358-70.

[68] Rudman A, Waldenstrom U. Critical views on postpartum care expressed by new mothers. BMC Health Serv Res 2007; 7: 178

[69] Ferber SG, Makhoul IR. The Effect of Skin-to-Skin Contact (Kangaroo Care) Shortly After Birth on the Neurobehavioural Responses of the Term Newborn: A randomized, controlled trial. Pediatrics 2004; 113(4): 858-65.

[70] Bergman N, Linley L, Fawcus S. Randomised controlled trial of skin-to-skin contact from birth versus conventional incubator for physiological stabilization in 1200- to 2199-gram newborns. Acta Paediatr 2004; 93: 779-85

[71] Ohgi S, Faked M, Moriuchi H, et al. The effects of kangaroo care on neonatal neurobehavioral organization, infant development and temperament in healthy low-birth- weight infants through one year. J Perinatol 2001; 22: 374-9.

[72] Feldman R, Eidelman AI, Sirota L, Weller A. Comaprison of skin to skin (kangaroo) and traditional care: parenting outcomes and preterm infant development. Pediatrics 2002; 110(1): 16-26.

[73] Feldman R, Eidelman AI. Skin-to-skin contact (Kangaroo Care) accelerates autonomic and neurobehavioural maturation in preterm infants. Dev Med Child Neurol 2003; 45(4): 274-81.

[74] Morgan BE, Horn AR, Bergman NJ. Should Neonates Sleep Alone? Biol Psychiatry 2011; 70(9): 817-25.

[75] Blum D. Love at Goon Park: Harry Harlow and the Science of Affection. Chichester: Wiley 2002.

[76] Pryce C, Aubert Y, Maier C, Pearce P, Fuchs E. The developmental impact of prenatal stress, prenatal dexamethasone and postnatal social stress on physiology, behaviour and neuroanatomy of primate offspring Studies in rhesus macaque and common marmoset. Psychopharmacology 2011; 214: 33-53.

[77] Pryce C, Aubert Y, Maier C, Pearce P, Fuchs E. Deprivation of parenting disrupts development of homeostatic and reward systems in marmoset monkey offspring. Biol Psychiatry 2004; 56: 72-29.

[78] Leventopoulos M, Russig H, Feldon J, Pryce C, Opacka-Juffry J. Early deprivation leads to long-term reductions in motivation for re- ward and 5-HT1A binding and both effects are reversed by fluoxetine. Neuropharmacology 2009; 56: 692-701.

[79] Hunter L, Rychnovsky J, Yount S. A selective review of maternal sleep characteristics in the postpartum period. J Obstet Gynacol Neonatal Nurs 2009; 38(1): 60-8.

[80] Albert J, Heinrichs-Breen J. An evaluation of a breastfeeding privacy sign to prevent interruptions and promote successful breastfeeding. J Obstet Gynacol Neonatal Nurs 2011; 40(3): 27480 .

[81] Yamauchi Y, Yamanouchi I. The relationsip between roomingin/not rooming-in and breast-feeding variables. Acta Paediatr Scand 1990; 79(11): 1017-22.

[82] Buxton K, Gielen A, Faden R, Brown C, Paige D, Chwalow A. Women intending to breastfeed: predictors of early infant feeding experiences. Am J Prev Med 1991;7(2): 101-6.

[83] Waldenstrom U, Swenson A. Rooming-in at night in the postpartum ward. Midwifery 1991; 7(2): 82-9.

[84] Young D. Rooming-in at night for mothers and babies: Sweden shows the way. Birth 2005; 32(3): 161-3.

[85] McKenna J. Sudden infant death syndrome in cross-cultural perspective: is infant- parent cosleeping protective? Ann Rev Anthropol 1996; 25: 201-16.

[86] Rigda RS, McMillen IC, Buckley P. Bed sharing patterns in a cohort of Australian infants during the first six months after birth. J Paediatr Child Health 2000; 36(2): 117-21.

[87] Quillin SI, Glenn L. Interaction between feeding method and cosleeping on maternal-newborn sleep. J Obstet Gynacol Neonatal Nurs 2004; 33(5): 580-8. 
[88] Baddock S, Galland B, Taylor B, Bolton D. Sleep arrangements and behaviour of bed-sharing families in the home setting. Pediatrics 2007; 119(1): e200-e7.

[89] Ball HL. Airway covering during bedsharing. Child Care Health Dev 2009; 35(5): 728-37.

[90] Moore E, Anderson G, Bergman N. Early skin-to-skin contact for mothers and their healthy newborn infants (review). Cochrane Database Syste Rev 2002; (5): CD003519.

[91] Johnston JM, Amico JA. A prospective longitudinal study of the release of oxytocin and prolactin in response to infant suckling in long term lactation. J Clin Endocrinol Metab 1986; 62(4): 653-7.

[92] Uvnas-Moberg K, Widstrom A-M, Werner S, Matthiesen A-S, Winberg J. Oxytocin and prolactin levels in breast-feeding women correlation with milk yield and duration of breast-feeding. Acta Obstet Gynecol Scand 1990; 69(4): 301-6.

[93] Neville MC, Morton J, Umemura S. Lactogenesis. The transition from pregnancy to lactation. Pediatr Clin North Am 2001; 48: 35 52.

[94] Chapman D, Perez-Escamilla R. Identification of risk factors for delayed onset of lactation. J Am Diet Assoc 1999; 99(4): 450-4.

[95] Sözmen M. Effects of early suckling of caesarean-born babies on lactation. Biol Neonate 1992; 62: 67-8.

[96] Ball HL, Klingaman KP. Breastfeeding and mother-infant sleep proximity: implications for infant care. In: Trevathan W, Smith EO, McKenna JJ, Eds. Evolutionary medicine and health: New perspectives. New York: Oxford University Press 2008; pp. 22641.

[97] Riordan J, Auerbach KG, Eds. Breastfeeding and human lactation. $2^{\text {nd }}$ ed. Boston, MA: Jones and Bartlett 1993.

[98] Marasco L, Barger J. Cue Feeding: wisdom and science. Breastfeed Abstracts 1999; 18(4): 28-9.

[99] Lawrence RA, Lawrence RM. Breastfeeding: A guide for the medical profession. $5^{\text {th }}$ ed. New York: C. V. Mosby 1999.

[100] Tennekoon KH, Arulambalam PD, Karunanayake EH, Seneviratne HR. Prolactin response to suckling in a group of fully breastfeeding women during the early postpartum period. Asia Oceania J Obstet Gynaecol 1994; 20(3): 311-9.

[101] Stuart-Macadam P. Biocultural perspectives on breastfeeding. In: Stuart-Macadam P, Dettwyler K, Eds. Breastfeeding: biocultural perspectives. New York: Aldine de Gruyter 1995; pp. 1-37.

[102] Ball H, Ward-Platt MP, Heslop E, Leech SJ, Brown KA. Randomised trial of infant sleep location on the postnatal ward. Arch Dis Child 2006; 91: 1005-10.

[103] Ball HL, Ward-Platt MP, Howel D, Russell C. Randomised trial of sidecar crib use on breastfeeding duration (NECOT). Arch Dis Child 2011; 96: 360-4.

[104] Gettler L, McKenna J. Never sleep with baby? Or keep me close but keep me safe: Eliminating Inappropriate "Safe Infant Sleep" Rhetoric in the United States. Cur Pediatr Rev 2010; 6(1): 71-7.

[105] Department of Health. Reduce the risk of cot death. London: Department of Health 2009.

[106] Scragg RKR, Mitchell EA, Stewart AW, et al. Infant room-sharing and prone sleep position in sudden infant death syndrome. Lancet 1996; 347: 7-12.

[107] Blair P, Fleming P, Smith I, et al. Babies sleeping with parents: case-control study of factors influencing the risk of the sudden infant death syndrome. BMJ 1999; 319: 1457-61

[108] Hauck FR, Herman SM, Donovan M, et al. Sleep environment and the risk of sudden infant death syndrome in an urban population: the Chicago infant mortality study. Pediatrics 2003; 111(5): 120714.

[109] Carpenter RG, Irgens LM, Blair PS, et al. Sudden unexplained infant death in 20 regions in Europe: case control study. Lancet 2004; 363: 185-91.

[110] Tappin D, Russell E, Brooke H. Bedsharing, roomsharing, and sudden infant death syndrome in Scotland: a case-control study. J Pediatr 2005; 147: 32-7.

[111] Blair P, Sidebotham P, Berry P, Evans M, Fleming P. Major epidemiological changes in sudden infant death syndrome: a 20 year population-based study in the UK. Lancet 2006; 367: 314-9.

[112] Blair PS, Sidebotham P, Evason-Coombe C, Edmonds M, Heckstall-Smith EMA, Fleming P. Hazardous cosleeping environments and risk factors amenable to change: case-control study of SIDS in south west England. Br Med J Online 2009; 339: $1-11$.
[113] Joyner B, Oden R, Ajao T, Moon R. Where should my baby sleep: a qualitative study of African American infant sleep location decisions. J Natl Med Assoc 2010; 102(10): 881-9.

[114] Blair P, Ball H. The prevalence and characteristics associated with parent- infant bed-sharing in England. Arch Dis Child 2004; 89: 1106-10.

[115] Clements MS, Mitchell EA, Wright SP, Esmail A, Jones DR, Ford RPK. Influences on breastfeeding in southeast england. Acta Paediatr 1997; 86(1): 51-6.

[116] Ford RPK, Mitchell EA, Scragg R, Stewart AW, Taylor BJ, Allen EM. Factors adversely associated with breast feeding in New Zealand. J Paediatr Child Health 1994; 30: 483-9.

[117] McCoy RC, Hunt CE, Lesko SM, et al. Frequency of bed sharing and its relationship to breastfeeding. J Dev Behav Pediatr 2004; 25(3): 141-9.

[118] Mitchell EA, Scragg L, Clements M. Factors related to infant bedsharing. N Z Med J 1994; 107: 466-7.

[119] Santos IS, Mota DM, Matijasevich A, Barros AJD, Barros FCF Bed-sharing at 3 Months and breast-feeding at 1 Year in Southern Brazil. J Pediatr 2009; 155: 505-9.

[120] McKenna JJ, Volpe LE. Sleeping with baby: An internet-based sampling of parental experiences, choices, perceptions and interpretations in a Western industrialized context. Infant Child Dev 2007; 16(4): 359-85.

[121] Ateah CA, Hamelin KJ. Maternal bedsharing practices, experiences, and awareness of risks. J Obstet Gynacol Neonatal Nurs 2008; 37: 274-81.

[122] Kendall-Tackett K, Cong Z, Hale T. Mother-Infant sleep locations and nighttime feeding behavior: U.S. Data from the survey of mothers' sleep and fatigue. Clin Lact 2010; 1: 27-31.

[123] Richard C, Mosko S. Sudden infant death syndrome in crosscultural perspective: Is infant-parent cosleeping protective? Ann Rev Anthropol 2004; 25: 201-16.

[124] Richard C, Mosko S, McKenna J, Drummond S. Sleeping position, orientation, and proximity in bedsharing infants and mothers. Sleep 1996; 19(9): 685-90.

[125] Baddock S, Galland B, Bolton D, Williams S, Taylor B. Differences in infant and parent behaviors during routine bedsharing compared to cot sleeping in the home setting. Pediatrics 2006; 117(5): 1599-607.

[126] Ball HL. Parent-infant bed-sharing behaviour at home. Peterhouse College, Cambridge: Foundation for the Study Of Infant Deaths Grant-holders' Conference 2001.

[127] Ball HL. Bed sharing on the postnatal ward: breastfeeding and infant sleep safety. Paediatr Child Health 2006; 11(Suppl A): 43A6 A.

[128] Ball HL. Parent-infant bed-sharing behavior: effects of feeding type, and presence of father. Hum Nat 2006; 17(3): 301-18.

[129] Task Force on Sudden Infant Death Syndrome. SIDS and Other Sleep-Related Infant Deaths: Expansion of recommendations for a safe infant sleeping environment.Technical Report. USA: American Academy of Pediatrics 2011.

[130] U.S.C.P.S.C. CPSC warns against placing babies in adult beds. Washington, DC: Office of Information and Public Affairs 1999.

[131] Safe sleep for your baby: reduce the risk of Sudden Infant Death Syndrome (SIDS). USA:NIH Pub. No. 05-7040 NICHD 2005.

[132] Blabey M, Gessner B. Infant bed-sharing practices and associated risk factors among births and infant deaths in Alaska. Public Health Rep 2009; 124: 527-34.

[133] Carpenter R. The hazards of bed sharing. Paediatr Child Health 2006; 11(Supplment A): 24-8.

[134] Vennemann MT, Findeisen M, Butterfab-Bahloul T, et al. Modifiable risk factors for SIDS in Germany: results of GeSID. Acta Paediatr 2005; 94: 655-60.

[135] Vennemann MM, Bajanowski T, Brinkmann B, et al. Sleep environment risk factors for sudden infant death syndrome: the German sudden infant death syndrome study. Pediatrics 2009; 123(4): 1162-70.

[136] Vennemann MM, Hense H-W, Bajanowski T, et al. Bed sharing and the risk of sudden infant death syndrome: Can we resolve the debate? J Pediatr 2012; 160(1): 44-8.

[137] Scheers NJ, Rutherford GW, Kemp JS. Where should infants sleep? A comparison of risk for suffocation of infants sleeping in cribs, adult beds, and other sleeping locations. Pediatrics 2003; 112(4): 883-9. 
[138] McKenna JJ. An anthropological perspective on the sudden infant death syndrome (SIDS): The role of parental breathing cues and speech breathing adaptations. Med Anthropol 1986; 10: 9-53.

[139] Jonas W, Nissen E, Ransiö-Arvidson A, Wiklund I, Henriksson P, Uvnäs-Moberg K. Short- and long-term decrease of blood pressure in women during breastfeeding. Breastfeed Med 2008; 3: 103-9.

[140] Hrdy SB. Mother nature: A history of mothers, infants, and natural selection. New York: Ballantine 1999.
[141] Blair P, Heron J, Fleming P. Relationship between bed-sharing and breastfeeding: longitudinal population-based analysis. Pediatrics 2010; 125(5): 1119-26.

[142] Ball HL, Moya E, Fairley L, Westman J, Oddie S, Wright J. Infant care practices related to sudden infant death syndrome in South Asian and White British families in the UK. Paediatr Perinatal Epidemiol 2012; 26(1): 3-12.

Received: February 27, 2012

Revised: November 24, 2012

Accepted: January 26, 2013

(C) Russell et al.; Licensee Bentham Open.

This is an open access article licensed under the terms of the Creative Commons Attribution Non-Commercial License (http://creativecommons.org/licenses/by$\mathrm{nc} / 3.0 /$ ), which permits unrestricted, non-commercial use, distribution and reproduction in any medium, provided the work is properly cited. 